\title{
Influence of Cognitive Reserve on Cognitive Trajectories
}

\section{Role of Brain Pathologies}

Xuerui Li, MSc, Ruixue Song, PhD, Xiuying Qi, PhD, * Hui Xu, PhD, Wenzhe Yang, MPH, Miia Kivipelto, MD, PhD, David A. Bennett, MD, $†$ and Weili Xu, PhD*†

Neurology ${ }^{\circledR}$ 2021;97:e1695-e1706. doi:10.1212/WNL.0000000000012728

\begin{abstract}
\section{Background and Objectives}

Evidence on the association of cognitive reserve (CR) with the cognitive trajectories is limited. We aimed to examine the influence of CR indicator on domain-specific cognitive trajectories taking brain pathologies into account.
\end{abstract}

\section{Methods}

Within the Rush Memory and Aging Project, 1,697 participants without dementia (mean age 79.6 years) were followed up to 21 years. CR indicator encompassing education, early-life, midlife, and late-life cognitive activities and late-life social activity was ascertained at baseline and categorized as tertiles (lowest, middle, and highest). Global cognition, episodic memory, semantic memory, working memory, visuospatial ability, and perceptual speed were assessed annually with 19 tests, from which composite scores were derived. During the follow-up, 648 participants died and underwent autopsies to evaluate brain pathologies. Data were analyzed using linear mixed-effect models.

\section{Results}

Among the participants, the score of the CR indicator ranged from -8.00 to 5.74 (mean $0.00 \pm$ 2.23). In multi-adjusted mixed-effect models, compared to the lowest $C R$, the highest was related to a slower decline in global cognition $(\beta=0.028,95 \%$ confidence interval $[\mathrm{CI}]$ $0.012-0.043$ ), episodic memory ( $\beta=0.028,95 \%$ CI $0.010-0.047$ ), and working memory ( $\beta=$ $0.019,95 \%$ CI $0.005-0.033$ ) during the follow-up. In brain pathologic data analysis, the association of the highest $\mathrm{CR}$ with cognitive function changes remained significant among participants with high Alzheimer disease pathology or gross infarcts.

\section{Discussion}

High CR indicator is associated with preserved global cognitive function, episodic memory, and working memory, even in the presence of brain pathologies. Our findings highlight the important role of high CR accumulation in the prevention of cognitive decline.

\author{
Correspondence \\ Dr. Xu \\ weili.xu@ki.se \\ or Xiuying Qi \\ qixiuying@tmu.edu.cn
}




\section{Glossary}

$\mathrm{AD}=$ Alzheimer disease; $\mathbf{B M I}=$ body mass index; $\mathbf{C I}=$ confidence interval; $\mathbf{C R}=$ cognitive reserve; $\mathbf{I Q R}$ = interquartile range; MCI = mild cognitive impairment; $\mathbf{M M S E}=$ Mini-Mental State Examination; $\mathrm{OR}=$ odds ratio; $\mathbf{S E}=$ standard error; SEM = structural equation modeling.

With population aging, cognitive impairment and dementia are common among older adults. Although there is a lack of efficacious treatment for dementia, a growing body of evidence suggests that dementia might be prevented by modifying certain risk factors. ${ }^{1}$ Many people may tolerate considerable dementia-related brain pathology without expressing the clinical syndrome of dementia. ${ }^{2}$ The concept of cognitive reserve (CR) explains such tolerance, and various life exposures seem to be associated with resilience against age- or pathology-related impairment of cognitive function. ${ }^{3}$

Educational attainment, socioeconomic status, social engagement, and cognitive activities are often regarded as proxies or measures of $\mathrm{CR}^{4,5}$ Numerous studies have indicated the association between individual CR-related factors and cognitive function in different domains, but with inconsistent findings. Several studies have shown that participants with higher education have better global cognitive function, ${ }^{6-9}$ but not all the domain-specific cognitive functions. ${ }^{8,10,11}$ Two longitudinal studies have suggested that high education may attenuate global cognitive decline in aging, ${ }^{12,13}$ while others showed no association between education and decline in any domain-specific cognitive function. ${ }^{14,15}$ Similarly, cognitive and social activities have been associated with cognitive function in some domains (including perceptual speed, executive function, and episodic memory). ${ }^{9,16,17}$ However, the relationship between cognitive/social stimulating activities and cognitive functioning remains controversial. ${ }^{18-21}$

Emerging evidence has shown that CR is a dynamic construct and influenced by different exposures across the lifespan. Thus, one reserve-enhancing factor at a certain period alone could not fully explain the accumulation of cognitive activities over the life course. ${ }^{22,23}$ Although few studies have suggested an association of high CR accumulated during life course with a decreased dementia risk, ${ }^{5,24,25}$ it is unclear about the association of $\mathrm{CR}$ with domain-specific cognitive decline (i.e., early-stage cognitive phenotype). High CR might directly counteract the accumulation of neuropathologies (such as $\beta$-amyloid), ${ }^{26}$ or bypass brain pathologies through other pathways to compensate for or cope with brain pathologies to delay dementia onset. $^{27,28}$ Therefore, the role of brain pathologies in the CRcognitive function association is in debate.

In the present study, we aimed to examine the associations of $\mathrm{CR}$ indicator with global and domain-specific cognitive function changes over time and to explore whether brain pathologies may play a role in such associations among dementia-free older adults.

\section{Methods}

\section{Study Population}

The Rush Memory and Aging Project is an ongoing prospective cohort study on aging and dementia. ${ }^{29}$ From 1997 through 2019, a total of 2,155 participants were annually followed up for a maximum of 21 years. Among all participants, we excluded 458 participants, including 115 with prevalent dementia (due to impaired cognitive function, eTable 1, doi. org/10.5061/dryad.59zw3r273), 282 with missing data on CRrelated factors, and 145 with missing data on cognitive function during the follow-up. Finally, 1,697 participants remained for the current study. During the follow-up, 795 participants died, of whom 648 (81.5\%) underwent autopsies (Figure 1).

\section{Standard Protocol Approvals, Registrations, and Patient Consents}

All participants provided written informed consent before their participation. The study was approved by the Institutional

Figure 1 Flowchart of the Study Population

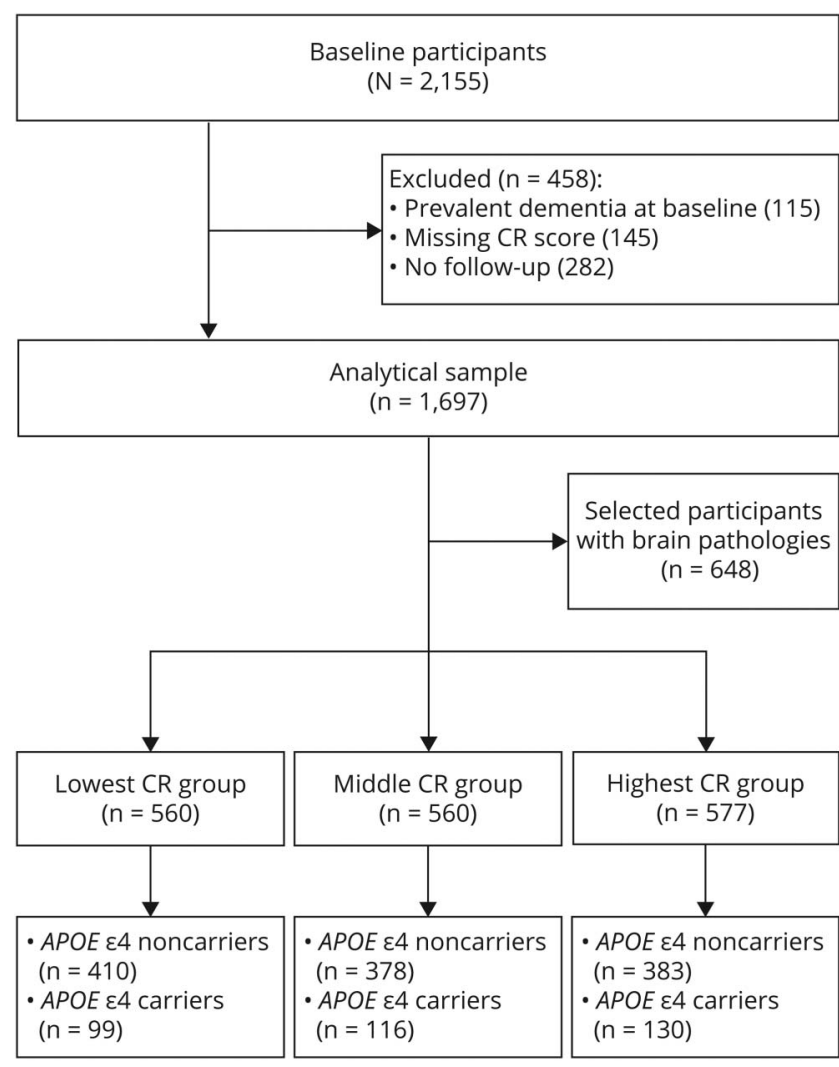

$\mathrm{CR}=$ cognitive reserve. 
Review Board of Rush University Medical Center and was performed following the ethical standards laid out in the 1964 Declaration of Helsinki and its later amendments. Anatomic Gift Act documentation was obtained from all participants who underwent autopsy. Participants signed a repository consent to allow their data to be shared.

\section{Data Collection}

At the time of enrollment and thereafter, all participants received a comprehensive clinical assessment (including medical and neurologic examinations and comprehensive cognitive function testing) by trained staff. Data on demographic characteristics (e.g., weight and height) and lifestyle factors (including alcohol drinking, smoking, and physical activity) were collected at study entry.

Alcohol drinking was assessed by the average amount (in grams) consumed per day during the past year. Smoking status was grouped into never, former, and current smoking. Physical activity was measured by summing up the hours that the participant engaged in activities per week using questions adapted from the National Health Interview Survey. ${ }^{30}$ Weight and height were measured at study entry by trained staff. Body mass index (BMI) was calculated as weight in kilograms divided by height in meters squared.

Hypertension was ascertained based on systolic blood pressure $\geq 140 \mathrm{~mm} \mathrm{Hg}$ or diastolic blood pressure $\geq 90 \mathrm{~mm} \mathrm{Hg}$ measured by mercury sphygmomanometer, self-reported history of hypertension, or the use of antihypertension drugs. Diabetes was defined by any of the following situations: hemoglobin A1c $\geq 6.5 \%$, fasting plasma glucose $\geq 126 \mathrm{mg} / \mathrm{dL}$, random blood glucose $\geq 200 \mathrm{mg} / \mathrm{dL}$, history of diabetes, and the use of diabetes medication. Heart diseases (including congestive heart failure, heart attack or coronary, coronary thrombosis, coronary occlusion, and myocardial infarction) were ascertained by self-reported information on medical conditions. Ascertainment of stroke was based on the clinicians' review of self-reported history of stroke or neurologic examination. APOE genotype was assessed by Polymorphic DNA Technologies and was dichotomized into $\varepsilon 4$ carrier and non- $\varepsilon 4$ carrier. Additional details about the data collection can be found online at the Rush Alzheimer's Disease Center Resource Sharing Hub (radc.rush.edu/docs/var/variables.htm).

\section{Assessment of CR Indicators}

Information on CR-related factors (including education, earlylife, mid-life, and late-life cognitive activities, late-life social activity, and late-life social network) was collected through personal interviews at study entry. The structured questionnaires on these factors were described in detail previously. ${ }^{5,31}$

Years of education were acquired based on the number of years of regular school reported at baseline. ${ }^{32}$ Cognitive activities in early life (including childhood [aged 6-12 years] and young adulthood [aged approximately 18 years]), midlife (aged approximately 40 years), and late life (during the past year of study enrollment) were assessed at baseline using a 37-item questionnaire of the frequency of participation in cognitively stimulating activities in the corresponding periods. Item scores in corresponding periods were averaged to yield cognitive activity measures (the score of early-life cognitive activity was obtained by further averaging the scores of cognitive activities in childhood and young adulthood). ${ }^{33}$ Higher scores indicate more participation in cognitive activities.

Late-life social activity was assessed with a 6-item scale questionnaire describing how often participants engaged in common types of activities that involved social interaction during the past year. The item scores were averaged to generate the composite measure of social activity and higher scores indicated more involvement in social activity. ${ }^{34,35}$ Latelife social network was quantified by standard questions regarding the number of children, family, and friends that each participant had and how often they interacted with them. ${ }^{36}$

The CR indicator was constructed using structural equation modeling (SEM). ${ }^{31}$ In the initial analysis of latent variables, education, early-/mid-/late-life cognitive activities, and late-life social activity and social network were included in the structural equation. However, the factor loading of social network was small (0.191) and the fitting degree of the equation was unsatisfactory, therefore late-life social network was excluded from the equation. Also, we intended to include physical activity in the SEM when initially creating CR indicator, but its factor loading was low (0.105), leading to an unsatisfactory model fitting. Thus, physical activity was excluded from the model as well. Finally, 5 CR-enhancing factors (i.e., education, early-, mid-, and late-life cognitive activities, and late-life social activity) were used to generate the final CR indicator (eFigure 1, doi.org/10.5061/dryad.59zw3r273).

The loadings of each factor were 0.505 (standard error [SE] $0.021, p<0.001$ ) for education, 0.752 (SE 0.015, $p<0.001)$ for early-life cognitive activity, 0.839 (SE 0.014, $p<0.001$ ) for midlife cognitive activity, 0.592 (SE 0.019, $p<0.001$ ) for late-life cognitive activity, and 0.360 (SE 0.024, $p<0.001$ ) for late-life social activity. The weight of the corresponding coefficient of the 5 factors from the SEM was 0.060 for education, 0.812 for early-life, 1.277 for mid-life, 0.383 for late-life cognitive activities, and 0.211 for late-life social activity. The final predicted value (as score) of the $\mathrm{CR}$ for each participant was generated by summing the products of standardized factors scores and the corresponding SEM-factor weights. The CR score ranged from -8.002 to 5.738 , with a higher score indicating a greater level of CR. CR indicator (score) was used as both a continuous and categorical variable (tertile: the lowest [as reference], middle, and the highest) in the following data analyses.

\section{Assessment of Cognitive Domains, Mild Cognitive Impairment, and Dementia}

Cognitive function was assessed via a battery of 21 cognitive performance tests administered at baseline and each year follow-up, as described previously. ${ }^{37}$ Of the tests, the MiniMental State Examination (MMSE) was used to describe the 
cohort and another test ("complex ideas") was only used to classify the diagnosis of cognitive function instead of being used in the analyses. The other 19 tests were used to assess performance in 5 cognitive domains: episodic memory (Word List Memory, Word List Recall, Word List Recognition, immediate and delayed recall of Story A from the Logical Memory subtest of the Wechsler Memory Scale-Revised, immediate and delayed recall of the East Boston Story), working memory (Digit Span Forward and Backward of the Wechsler Memory Scale-Revised and Digit Ordering), semantic memory (Verbal Fluency, Boston Naming Test, the National Adult Reading Test), perceptual speed (oral version of the Symbol Digit Modalities Test, Number Comparison, 2 indices from a modified Stroop Neuropsychological Screening Test), and visuospatial ability (Judgment of Line Orientation, Standard Progressive Matrices). All the raw scores of the tests were individually converted to $z$ scores, which were further averaged to yield a global cognitive function, ${ }^{38,39}$ with higher scores indicating better cognitive function.

The assessments of dementia and mild cognitive impairment (MCI) were based on a 3-stage procedure involving computer scoring of cognitive tests, clinical judgment by a neuropsychologist, and diagnostic classification by an experienced clinician. ${ }^{40,41}$ Clinical diagnosis of dementia was based on the criteria of the joint working group of the National Institute of Neurologic and Communicative Disorders and Stroke and the Alzheimer's Disease and Related Disorders Association. ${ }^{40}$ The diagnosis of MCI was rendered for persons who were judged to have cognitive impairment but not meet the criteria for dementia by the neuropsychologist and clinician. ${ }^{41}$

\section{Assessment of Brain Pathologies}

Brain pathologies were evaluated in 648 deceased participants (median postmortem interval 7 hours [interquartile range (IQR) 5.75-9.25]). The neurologists followed a standard protocol for tissue preservation, tissue sectioning, and quantification of pathologic findings, as detailed in a previous study. ${ }^{42}$ Global Alzheimer disease (AD) pathology burden (including diffuse and neuritic plaques and neurofibrillary tangles) was quantified ${ }^{42}$ and dichotomized as low or high based on its median. Chronic infarcts (including gross infarcts and microinfarcts), ${ }^{43}$ cerebral vascular disease pathology (including atherosclerosis, arteriolosclerosis, and cerebral amyloid angiopathy), Lewy bodies, and typical hippocampal sclerosis ${ }^{5}$ were assessed as present or absent.

\section{Statistical Analysis}

The characteristics of study participants at study entry by different CR groups were compared using one-way analysis of variance/Wilcoxon rank-sum tests for continuous variables and $\chi^{2}$ tests for categorical variables.

The $\beta$ coefficients and 95\% confidence intervals (CIs) of the associations between $\mathrm{CR}$ indicator (including continuous and categorical CR) and annual change in global cognitive function and 5 cognitive domains were estimated using linear mixed- effect models, with follow-up time (in years) as the time scale. The fixed effect included CR indicator, follow-up time, and their interaction. To allow for the individual differences at baseline and over time, we included random effects for the intercept and slope for the time in the model. When CR was used as a continuous variable, each point change of cognitive function responded to a unit change of CR indicator. When CR indicator was used as a categorical variable (tertile), the points change in cognitive function were corresponding to the middle or highest CR in comparison to the lowest. Age, sex, BMI, smoking status, alcohol consumption, physical activity, hypertension, diabetes, heart disease, stroke, and $A P O E \varepsilon 4$ were considered as potential confounders. To further explore the role of $A P O E \varepsilon 4$ in the relationship between $C R$ indicator and cognitive function, an interaction term between $\mathrm{CR}$ and $A P O E$ $\varepsilon 4$ status was included in the models first; then, stratified analysis was performed according to APOE $\varepsilon 4$.

Among the participants with autopsies, the odds ratios (ORs) with $95 \%$ CI of the relationships between CR indicator and brain pathologies were estimated using multinomial logistic regression. Linear mixed-effect models were used again to explore the association of $\mathrm{CR}$ indicator with cognitive function by different levels of brain pathologies. In the sensitivity analysis, we repeated the linear mixed-effect models by excluding 433 individuals with $\mathrm{MCI}$ at baseline and imputing missing values for covariates. A 2-tailed $p$ value $<0.05$ was considered to be statistically significant for all tests. All statistical analyses were performed using Stata SE 15.0 for Windows (StataCorp).

\section{Data Availability}

Data requests can be made at radc.rush.edu or available from the corresponding author on reasonable request. The results of supplementary analyses are available from Dryad (eTables 1-13 and eFigure 1, doi.org/10.5061/dryad.59zw3r273).

\section{Results}

\section{Characteristics of the Study Population at Baseline}

Among the 1,697 dementia-free participants (mean age: 79.6 \pm 7.5 years, female: $75.7 \%$ ), 560 (33\%), 560 (33\%), and 577 (34\%) were included in the lowest, middle, and highest CR groups, respectively. Compared to the lowest CR group, participants with the highest CR were more likely to have physical activity, better global cognitive function, and higher scores of MMSE, episodic memory, semantic memory, working memory, visuospatial ability, and perceptual speed, but less likely to have diabetes. There were no significant differences in terms of age, sex, BMI, APOE $\varepsilon 4$, hypertension, heart disease, or stroke among the 3 groups (Table 1).

\section{Relationship Between CR Indicator and Cognitive Decline}

At baseline, when the $\mathrm{CR}$ indicator was operationalized as a continuous variable, a higher score was associated with better 
global cognitive function and 5 cognitive domains (episodic memory, semantic memory, working memory, visuospatial ability, and perceptual speed). When the CR indicator was analyzed as a categorical variable (tertiles), participants with the highest CR had better cognitive function in all domains compared to those with the lowest $\mathrm{CR}$.
During the follow-up (median 5.31 years, IQR 2.61-8.80 years), the CR indicator was associated with a slower rate of decline in global cognition, episodic memory, semantic memory, working memory, and perceptual speed over time in multi-adjusted mixed-effect models. Compared to the lowest $\mathrm{CR}$, the highest was associated with a slower decline in global

Table 1 Characteristics of the Study Population by Tertiles of Cognitive Reserve at Baseline $(n=1,697)$

\begin{tabular}{|c|c|c|c|c|}
\hline \multirow[b]{2}{*}{ Characteristics } & \multicolumn{3}{|l|}{ Cognitive reserve $^{a}$} & \multirow[b]{2}{*}{$p$ Value } \\
\hline & Lowest $(n=560)$ & Middle $(n=560)$ & Highest $(n=577)$ & \\
\hline Age, y & $79.62 \pm 8.06$ & $79.84 \pm 7.47$ & $79.33 \pm 6.95$ & 0.521 \\
\hline Female & $421(75.2)$ & $422(75.4)$ & $441(76.4)$ & 0.868 \\
\hline \multicolumn{5}{|l|}{ Life course cognitive reserve } \\
\hline Years of education & $13.2 \pm 3.29$ & $14.97 \pm 2.71$ & $16.43 \pm 2.92$ & $<0.001$ \\
\hline Early-life cognitive activity & $2.45 \pm 0.47$ & $3.08 \pm 0.35$ & $3.58 \pm 0.37$ & $<0.001$ \\
\hline Mid-life cognitive activity & $2.62 \pm 0.48$ & $3.33 \pm 0.29$ & $3.89 \pm 0.32$ & $<0.001$ \\
\hline Late-life cognitive activity & $2.69 \pm 0.62$ & $3.19 \pm 0.55$ & $3.68 \pm 0.50$ & $<0.001$ \\
\hline Late-life social activity & $2.40 \pm 0.55$ & $2.66 \pm 0.53$ & $2.91 \pm 0.51$ & $<0.001$ \\
\hline Social network & $5.00(2.00-8.00)$ & $6.00(3.00-9.00)$ & $6.00(4.00-11.00)$ & $<0.001$ \\
\hline $\mathrm{BMI}, \mathrm{kg} / \mathrm{m}^{2}$ & $27.78 \pm 5.87$ & $27.32 \pm 5.05$ & $27.18 \pm 5.23$ & 0.151 \\
\hline Alcohol consumption, g/d & $0.00(0.00-2.40)$ & $0.00(0.00-7.12)$ & $1.32(0.00-8.32)$ & $<0.001$ \\
\hline \multicolumn{5}{|l|}{ Smoking status } \\
\hline Never & $313(56.0)$ & $343(61.4)$ & $341(59.1)$ & 0.021 \\
\hline Previous smoker & $221(39.5)$ & $207(37.0)$ & $224(38.8)$ & \\
\hline Current smoker & $25(4.5)$ & $9(1.6)$ & $12(2.1)$ & \\
\hline Physical activity, h/wk & $1.88(0.38-4.17)$ & $2.50(1.13-4.82)$ & $3.00(1.33-5.17)$ & $<0.001$ \\
\hline APOE \&4 carriers & 99 (19.4) & $117(23.7)$ & $129(25.1)$ & 0.081 \\
\hline Diabetes & $106(18.9)$ & $75(13.4)$ & $54(9.4)$ & $<0.001$ \\
\hline Hypertension & $390(69.6)$ & $381(68.0)$ & $392(67.9)$ & 0.787 \\
\hline Heart disease & $70(13.0)$ & 64 (11.9) & $58(11.0)$ & 0.599 \\
\hline Stroke & $56(11.1)$ & $47(9.1)$ & $39(7.3)$ & 0.104 \\
\hline MMSE & $27.60 \pm 2.29$ & $28.12 \pm 1.79$ & $28.49 \pm 1.59$ & $<0.001$ \\
\hline Global cognition & $-0.13 \pm 0.56$ & $0.12 \pm 0.51$ & $0.31 \pm 0.47$ & $<0.001$ \\
\hline Episodic memory & $-0.06 \pm 0.66$ & $0.13 \pm 0.65$ & $0.30 \pm 0.59$ & $<0.001$ \\
\hline Semantic memory & $-0.21 \pm 0.69$ & $0.15 \pm 0.58$ & $0.35 \pm 0.53$ & $<0.001$ \\
\hline Working memory & $-0.16 \pm 0.74$ & $0.10 \pm 0.75$ & $0.27 \pm 0.72$ & $<0.001$ \\
\hline Visuospatial ability & $-0.17 \pm 0.84$ & $0.06 \pm 0.75$ & $0.28 \pm 0.75$ & $<0.001$ \\
\hline Perceptual speed & $-0.17 \pm 0.81$ & $0.11 \pm 0.74$ & $0.33 \pm 0.68$ & $<0.001$ \\
\hline Brain pathology assessed & $228(40.7)$ & $213(38.0)$ & $207(35.9)$ & 0.243 \\
\hline
\end{tabular}

Abbreviations: $\mathrm{BMI}=$ body mass index; MMSE = Mini-Mental State Examination.

Values are mean $\pm \mathrm{SD}, \mathrm{n}(\%)$, or median (interquartile range). Missing data: $\mathrm{BMI}=31$; alcohol consumption $=2 ;$ smoking status $=2 ; A P O E \varepsilon 4$ genotype $=181$; heart disease $=92 ;$ stroke $=140 ;$ MMSE $=1$.

a Cognitive reserve categories: lowest group, -8.002 to -0.826 ; middle group, -0.827 to 1.062 ; highest group, 1.063 to 5.738 . 
cognition, episodic memory, and working memory over the follow-up. However, no statistically significant association of the middle CR with cognitive function decline was shown (Table 2).

There was no statistically significant interaction between CR indicator and $A P O E \varepsilon 4$ on cognitive decline (all $p$ values > 0.05 ). However, in the stratified analysis by APOE $\varepsilon 4$, the associations of higher $\mathrm{CR}$ with a slower decline in global and domain-specific cognitive function were present only among APOE \&4 noncarriers (Table 3 ).

\section{Role of Brain Pathologies in the CR-Cognitive Decline Association}

During the follow-up, 795 participants died; of them, 648 (81.5\%) underwent autopsies. In multi-adjusted multinomial logistic regression analyses, the highest $\mathrm{CR}$ was related to a lower burden of global $\mathrm{AD}$ pathology (OR $0.66,95 \% \mathrm{CI}$ $0.45-0.98$ ), neuritic plaque (OR $0.75,95 \%$ CI $0.57-1.00, p=$ 0.047 ), and gross infarcts (OR $0.47,95 \%$ CI $0.29-0.76$ ), but not related to other brain pathologies compared to the lowest CR (Table 4). When the CR indicator was used as a continuous variable, similar results were shown (eTable 2, doi.org/10. 5061/dryad.59zw3r273).

Among the participants who underwent autopsies, the association between the highest $\mathrm{CR}$ and slower decline in global cognitive function, episodic memory, working memory, or visuospatial ability remained significant after additional adjustment for brain pathologies (Figure 2 and eTables 3 and 4 , doi.org/10.5061/dryad.59zw3r273).

In stratified analysis by the level of brain pathologies, the effect of the highest CR indicator on a slower decline in global cognitive function, but not domain-specific cognitive function, remained significant in participants with high $\mathrm{AD}$ pathology or gross infarcts (Figure 3 and eTables 5-6, doi.org/ 10.5061/dryad.59zw3r273).

\section{Supplementary Analysis}

Similar results to those from the main analyses were obtained when we repeated the analysis by (1) excluding 433 individuals with MCI at baseline (eTable 7, doi.org/10.5061/dryad. 59zw3r273), (2) performing multiple imputations for missing

Table $2 \beta$ Coefficients (95\% Confidence Intervals) for the Association of Cognitive Reserve (CR) With Changes of Global Cognitive Function and Cognitive Function in Different Domains Over Follow-up Time: Results From Linear Mixed-Effects Models

\begin{tabular}{|c|c|c|c|c|c|c|}
\hline CR & Global cognition & Episodic memory & Semantic memory & Working memory & Visuospatial ability & Perceptual speed \\
\hline \multicolumn{7}{|l|}{ Baseline } \\
\hline \multirow[t]{2}{*}{ Continuous CR } & $0.089^{a}$ & $0.080^{a}$ & $0.112^{a}$ & $0.089^{a}$ & $0.095^{a}$ & $0.105^{a}$ \\
\hline & (0.077 to 0.102 ) & (0.064 to 0.095$)$ & (0.097 to 0.127$)$ & (0.072 to 0.106$)$ & (0.077 to 0.113 ) & (0.087 to 0.122$)$ \\
\hline \multicolumn{7}{|l|}{ Categories CR } \\
\hline Lowest & Reference & Reference & Reference & Reference & Reference & Reference \\
\hline \multirow[t]{2}{*}{ Middle } & $0.225^{a}$ & $0.184^{a}$ & $0.341^{a}$ & $0.210^{a}$ & $0.242^{a}$ & $0.274^{a}$ \\
\hline & (0.158 to 0.293$)$ & (0.101 to 0.266$)$ & (0.259 to 0.422$)$ & (0.118 to 0.303$)$ & (0.146 to 0.338$)$ & (0.179 to 0.369$)$ \\
\hline \multirow[t]{2}{*}{ Highest } & $0.421^{a}$ & $0.361^{a}$ & $0.533^{a}$ & $0.409^{a}$ & $0.471^{a}$ & $0.507^{a}$ \\
\hline & (0.353 to 0.489$)$ & $(0.278$ to 0.444$)$ & $(0.450$ to 0.615$)$ & $(0.316$ to 0.502$)$ & (0.374 to 0.568$)$ & (0.411 to 0.602$)$ \\
\hline \multicolumn{7}{|l|}{ Longitudinal } \\
\hline \multirow[t]{2}{*}{ Continuous CR $\times$ time } & $0.005^{\mathrm{a}}$ & $0.005^{\mathrm{a}}$ & $0.003^{a}$ & $0.004^{a}$ & 0.002 & $0.003^{a}$ \\
\hline & (0.003 to 0.008$)$ & (0.002 to 0.009$)$ & (0.000 to 0.007$)$ & (0.001 to 0.006$)$ & $(-0.000$ to 0.005$)$ & (0.000 to 0.006$)$ \\
\hline \multicolumn{7}{|l|}{ Categories CR $\times$ time } \\
\hline Lowest $\times$ time & Reference & Reference & Reference & Reference & Reference & Reference \\
\hline \multirow[t]{2}{*}{ Middle $\times$ time } & 0.015 & 0.017 & 0.009 & 0.014 & 0.007 & -0.004 \\
\hline & $(-0.001$ to 0.031$)$ & $(-0.002$ to 0.035$)$ & $(-0.008$ to 0.026$)$ & $(-0.000$ to 0.028$)$ & $(-0.007$ to 0.021$)$ & $(-0.019$ to 0.012$)$ \\
\hline \multirow[t]{2}{*}{ Highest $\times$ time } & $0.028^{a}$ & $0.028^{a}$ & 0.017 & $0.019^{a}$ & 0.013 & 0.010 \\
\hline & (0.012 to 0.043$)$ & (0.010 to 0.047$)$ & $(-0.000$ to 0.034$)$ & (0.005 to 0.033$)$ & $(-0.000$ to 0.027$)$ & $(-0.005$ to 0.025$)$ \\
\hline
\end{tabular}

Adjusted for age, sex, body mass index, smoking, alcohol consumption, physical activity, hypertension, stroke, heart disease, diabetes, and $A P O E$ \&4. ${ }^{a} p<0.05$. 
Table $3 \beta$ Coefficients (95\% Confidence Intervals) for the Longitudinal Association of Cognitive Reserve (CR) With Changes in Global Cognitive Function and Cognitive Function in Different Domains Over Follow-up, Stratified by $A P O E \& 4$

\begin{tabular}{|c|c|c|c|c|c|c|}
\hline CR & Global cognition & Episodic memory & Semantic memory & Working memory & Visuospatial ability & Perceptual speed \\
\hline \multicolumn{7}{|l|}{ APOE \&4 noncarriers } \\
\hline \multirow[t]{2}{*}{ Continuous CR $\times$ time } & $0.006^{a}$ & $0.007^{a}$ & $0.004^{a}$ & $0.004^{a}$ & $0.003^{\mathrm{a}}$ & 0.003 \\
\hline & (0.003 to 0.009$)$ & (0.003 to 0.010$)$ & (0.001 to 0.007$)$ & (0.001 to 0.007$)$ & (0.000 to 0.005$)$ & $(-0.000$ to 0.006$)$ \\
\hline \multicolumn{7}{|l|}{ Categories $\mathrm{CR} \times$ time } \\
\hline Lowest $\times$ time & Reference & Reference & Reference & Reference & Reference & Reference \\
\hline \multirow[t]{2}{*}{ Middle $\times$ time } & $0.021^{a}$ & $0.023^{a}$ & $0.020^{a}$ & $0.017^{a}$ & 0.012 & -0.003 \\
\hline & (0.005 to 0.038$)$ & (0.004 to 0.042$)$ & (0.003 to 0.037$)$ & (0.003 to 0.031$)$ & $(-0.002$ to 0.026$)$ & $(-0.019$ to 0.014$)$ \\
\hline \multirow[t]{2}{*}{ Highest $\times$ time } & $0.029^{a}$ & $0.032^{a}$ & $0.020^{\mathrm{a}}$ & $0.019^{a}$ & $0.017^{a}$ & 0.010 \\
\hline & (0.013 to 0.045$)$ & (0.013 to 0.051$)$ & (0.003 to 0.037$)$ & (0.005 to 0.033$)$ & (0.003 to 0.031$)$ & $(-0.006$ to 0.026$)$ \\
\hline \multicolumn{7}{|l|}{ APOE \&4 carriers } \\
\hline \multirow[t]{2}{*}{ Continuous CR $\times$ time } & 0.005 & 0.004 & 0.003 & 0.004 & 0.001 & 0.004 \\
\hline & $(-0.002$ to 0.013$)$ & $(-0.005$ to 0.012$)$ & $(-0.006$ to 0.011$)$ & $(-0.003$ to 0.011$)$ & $(-0.005$ to 0.007$)$ & $(-0.003$ to 0.011$)$ \\
\hline \multicolumn{7}{|l|}{ Categories $\mathrm{CR} \times$ time } \\
\hline Lowest $\times$ time & Reference & Reference & Reference & Reference & Reference & Reference \\
\hline \multirow[t]{2}{*}{ Middle $\times$ time } & -0.003 & -0.003 & -0.028 & 0.003 & -0.011 & -0.004 \\
\hline & $(-0.046$ to 0.039$)$ & $(-0.052$ to 0.046$)$ & $(-0.077$ to 0.020$)$ & $(-0.036$ to 0.043$)$ & $(-0.048$ to 0.026$)$ & $(-0.043$ to 0.036$)$ \\
\hline \multirow[t]{2}{*}{ Highest $\times$ time } & 0.033 & 0.026 & 0.011 & 0.024 & 0.004 & 0.019 \\
\hline & $(-0.007$ to 0.074$)$ & (-0.021 to 0.073$)$ & $(-0.036$ to 0.057$)$ & $(-0.013$ to 0.062$)$ & (-0.031 to 0.038$)$ & $(-0.019$ to 0.057$)$ \\
\hline
\end{tabular}

Adjusted for age, sex, body mass index, smoking, alcohol consumption, physical activity, hypertension, stroke, heart disease, and diabetes. a $p<0.05$.

values of covariates $(\mathrm{n}=434)$ (eTable 8 , doi.org/10.5061/dryad. 59zw3r273), (3) removing late-life measures (late-life cognitive activity and social activity), mid-life measure (mid-life cognitive activity), or early-life measures (education and early-life cognitive activity) from SEM, separately (eTables 9-11, doi.org/10.5061/ dryad.59zw3r273), (4) using individual CR-related factors (eTable 12, doi.org/10.5061/dryad.59zw3r273), and (5) in addition adjusting for survival status during the follow-up (eTable 13, doi.org/10.5061/dryad.59zw3r273).

\section{Discussion}

In the community-based longitudinal study among dementiafree older adults with neuropathologic data available in a subsample, we found that (1) high CR indicator composed of education, early-life, mid-life, and late-life cognitive activities and late-life social activity predicted preserved cognitive functioning in global cognition, episodic memory, and working memory; and (2) the association of high CR indicator with a slower decline in cognitive function remained significant in the presence of high $\mathrm{AD}$ pathology or gross infarcts.
In the past 10 years, since the CR concept emerged, the research to explore the relationship between $\mathrm{CR}$ and cognitive decline has been stimulated with widespread interest. Thus far, the majority of cross-sectional studies on the association between individual CR-related factors and cognitive function have consistently documented that people with higher education attainment, frequent participation in cognitively stimulating activities, or social activities may have better cognitive function. ${ }^{7-9,16,17,44}$ However, results from longitudinal studies addressing the association of CR-related factors with the decline in cognitive function are inconsistent. In a 12-year follow-up study, educational years were not related to rates of change over time of any cognitive domain. ${ }^{14}$ Another study of older Americans ( $\geq 70$ years) has shown that a higher level of education is linked to a faster cognitive decline of verbal memory. ${ }^{12}$ Besides, some studies have demonstrated that more frequent cognitive activity is associated with reduced rates of decline in episodic memory, semantic memory, and perceptual speed, but not working memory or visuospatial ability, ${ }^{18}$ and that more frequent cognitive activity in early life ${ }^{21}$ or across the lifespan ${ }^{42}$ is associated with slower late-life cognitive decline. However, cognitive activity is not related to 
Table 4 Association of the Middle and Highest Cognitive Reserve (CR) at Baseline With Brain Pathologies (the Lowest CR as Reference)

\begin{tabular}{|c|c|c|}
\hline Brain pathologies ${ }^{a}$ & $\begin{array}{l}\text { Middle CR } \\
(n=213)\end{array}$ & $\begin{array}{l}\text { Highest CR } \\
(n=207)\end{array}$ \\
\hline \multicolumn{3}{|l|}{ AD pathologies } \\
\hline Global AD pathology & $0.77(0.53-1.13)$ & $0.66(0.45-0.98)$ \\
\hline Diffuse plaque & $0.95(0.72-1.27)$ & $0.88(0.65-1.19)$ \\
\hline Neuritic plaque & $0.89(0.69-1.16)$ & $0.75(0.57-1.00)^{\mathrm{b}}$ \\
\hline Neurofibrillary tangles & $0.98(0.96-1.01)$ & $0.98(0.95-1.01)$ \\
\hline \multicolumn{3}{|l|}{ Chronic infarcts } \\
\hline Gross infarcts & $0.77(0.50-1.19)$ & $0.47(0.29-0.76)$ \\
\hline Microscopic infarcts & $0.92(0.59-1.43)$ & $0.74(0.45-1.20)$ \\
\hline \multicolumn{3}{|l|}{ Vascular disease pathology } \\
\hline Cerebral atherosclerosis & $0.70(0.41-1.18)$ & $0.93(0.53-1.64)$ \\
\hline Cerebral amyloid angiopathy & $0.72(0.43-1.20)$ & $0.85(0.50-1.46)$ \\
\hline Arteriolosclerosis & $1.11(0.70-1.77)$ & $1.51(0.94-2.47)$ \\
\hline Lewy bodies & $1.13(0.69-1.87)$ & $1.11(0.65-1.88)$ \\
\hline Hippocampal sclerosis & $0.56(0.25-1.23)$ & $1.24(0.61-2.53)$ \\
\hline
\end{tabular}

Abbreviation: $A D=$ Alzheimer disease.

Values are odds ratio ( $95 \%$ confidence interval). Adjusted for age, sex, body mass index, smoking, alcohol consumption, physical activity, hypertension, stroke, heart disease, diabetes, and APOE $\& 4$.

${ }^{a} \mathrm{AD}$ pathologies were continuous measures and the other brain pathologies were dichotomous measures (present/absent).

${ }^{\mathrm{b}} \mathrm{p}<0.05$.

change in cognitive performance over $2-3$ years follow-up in another report. ${ }^{19}$ Furthermore, the longitudinal study within the Betula project has shown that social activity is a predictor of episodic memory, but there is no influence of social activity on semantic memory. ${ }^{20}$ Possible explanations for the discrepancies could be the differences in the assessments of CR indicators, follow-up time, and characteristics of study populations among these studies.

Heretofore, the evidence on the relationship between the composite index of CR and cognitive decline has been relatively limited. In our study, we used SEM to yield the CR indicator based on educational and mentally stimulating activities throughout the life course. ${ }^{31}$ To our knowledge, this is the first study to explore the association between life course $\mathrm{CR}$ indicator and decline of cognitive function in specific domains. We found that a higher CR indicator was associated with not only better baseline cognitive function, but also preserved cognitive functioning in global cognition, episodic memory, and working memory longitudinally.

It is well-known that $A P O E \varepsilon 4$ is an established risk factor for cognitive decline and the development of dementia. ${ }^{45}$ In the current study, we found that the association of higher CR indicator with slower cognitive decline was present only among $A P O E \varepsilon 4$ noncarriers, but not in $A P O E \varepsilon 4$ carriers. However, the interaction between $\mathrm{CR}$ indicator and $A P O E \varepsilon 4$ on cognitive decline was not significant. These results might be due to the fact that $A P O E \& 4$ carriers who had developed dementia were excluded at baseline, or insufficient power caused by the small sample of APOE $\varepsilon 4$ carriers in our study.

The relationship between brain pathology and cognitive function is increasingly recognized to be complex. The role of brain pathology in the CR-dementia association has been explored, and 2 hypotheses have been proposed. One is that $\mathrm{CR}$ might be directly associated with neuropathology, such as reducing the deposition of $\beta$-amyloid in aging. ${ }^{26}$ Another suggests that CR may delay the onset of dementia by compensating for or coping with brain pathology through other pathways, ${ }^{27,46}$ such as a higher neuronal density and greater cortical thickness, ${ }^{47}$ thus presenting the ability to effectively use the brain network. ${ }^{3}$ To explore the role of brain pathologies in the CR-cognitive decline association, in the second part of our study, we found that the highest CR was weakly related to global $\mathrm{AD}$ pathology and gross infarcts, suggesting that CR might exert a slight neuroprotective effect in cognitively normal older adults. However, the association of the highest CR indicator with preserved cognitive function over time was still significant after adjusting for these brain pathologies, and this association remained significant even among participants with high global $\mathrm{AD}$ pathology or gross infarcts. Our results may support the 2 hypotheses mentioned above.

The possible mechanisms underlying the association between $\mathrm{CR}$ and cognitive function are not clear. Environmental enrichment has been related to a variety of neuroplastic responses (such as the formation of new neurons and synapses) in brain regions that are critically involved in cognitive functioning in animals. ${ }^{48}$ In humans, education promotes cognitive processing and brain networking, leading to slower cognitive declines in the presence of neuropathology. ${ }^{49}$ Frequent mental activity and social engagement may contribute to structural and functional reorganization, making neural systems involved in the activities less disrupted by $\mathrm{AD}$ pathology. ${ }^{50}$ Mental activity and social engagement may also increase synaptic density in the cortex through stimulation, so that cognitive functioning in unaffected neurons might be able to compensate for the loss of function in affected brain areas in a pathologic process. ${ }^{20}$ Thus, individuals with high CR may develop more alternative neural networks to maintain cognitive function. However, further research is needed to identify the structural, biochemical, and molecular mechanisms of the brain's ability to withstand brain pathologies.

A notable strength of our study is the community-based prospective cohort with a relatively large sample size and longterm follow-up. Furthermore, the use of latent variable could capture CR-related factors from different periods over the life course. Nevertheless, some limitations of our study should be 
Figure 2 Cognitive Trajectories in Global Cognition and Different Domains by Cognitive Reserve (CR) in Tertiles Further Adjusted by Brain Pathology
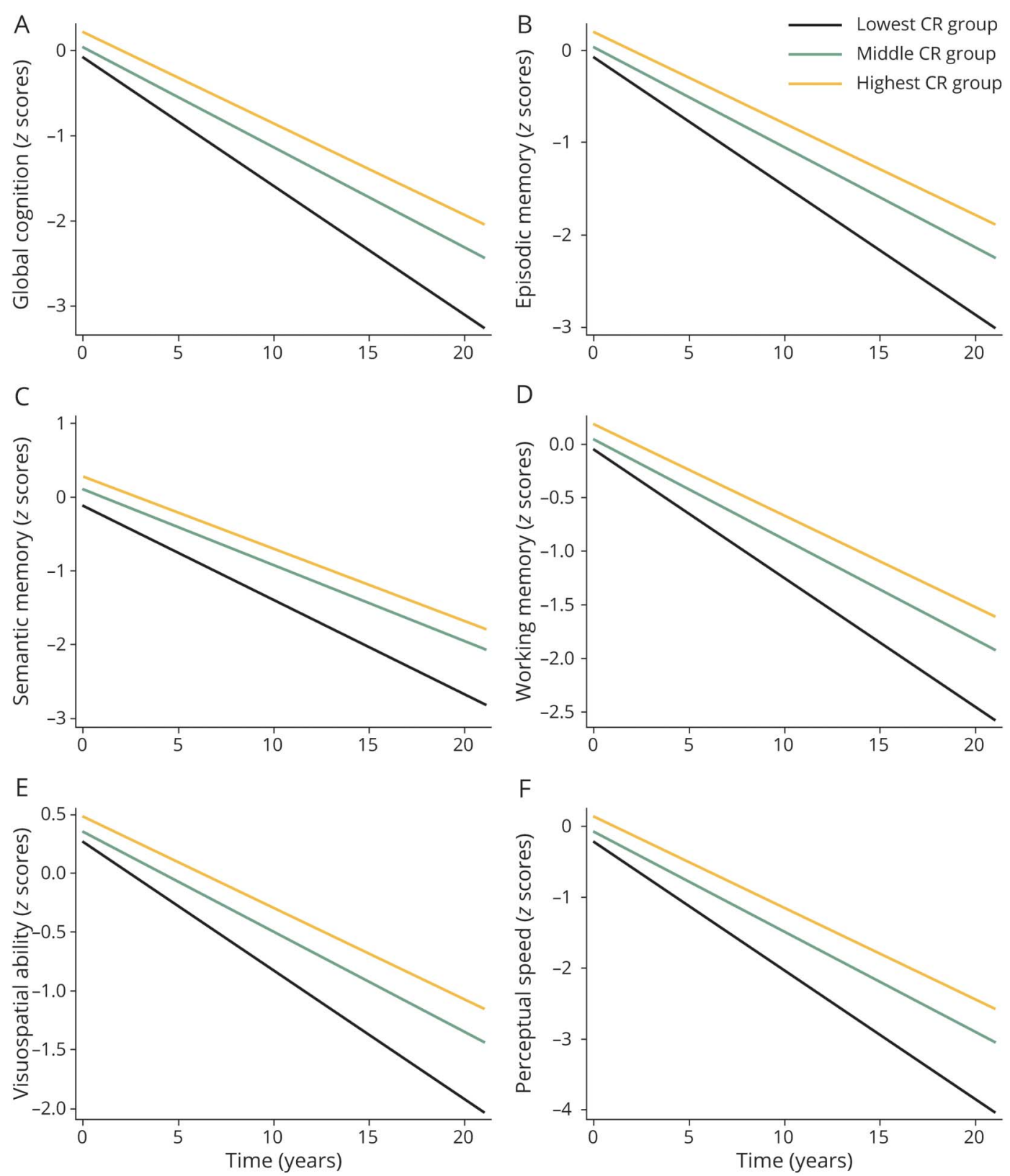

(A-F) Trajectories represent $\beta$ coefficients from linear mixed-effect models adjusted for age, sex, body mass index, smoking, alcohol consumption, physical activity, hypertension, stroke, heart disease, diabetes, $A P O E \& 4$, global Alzheimer disease (AD) pathology, and gross infarcts (the lowest CR as reference).

pointed out. First, the participants were volunteers with a mean age of 79.6 years at study entry. Thus, caution is required when generalizing our findings, especially the results regarding brain pathology, to the younger population. Second, the CR-related factors were ascertained through retrospective self-reported information, which might lead to some measurement errors. However, using the SEM to extract the CR indicator might attenuate some of the errors. Furthermore, information on occupation was not available, and thus could not be considered in CR indicator. Third, the brains of the participants were obtained and autopsied when the participants were deceased, and the exact time brain pathologies occurred was unknown. Finally, all participants were living in urban areas, thus caution is needed when generalizing our findings to older adults living in rural areas. In addition, data on nutrition were not available for all participants, and nutrition could not be taken into account in the data analysis.

This study provides evidence that high CR indicator assessed by education; early-life, mid-life, and late-life cognitive activities; and late-life social activity may preserve cognitive 
Figure 3 Cognitive Trajectories in Global Cognitive Function by Cognitive Reserve (CR) (Lowest CR as Reference) and Brain Pathology

A. Low global AD pathology burden

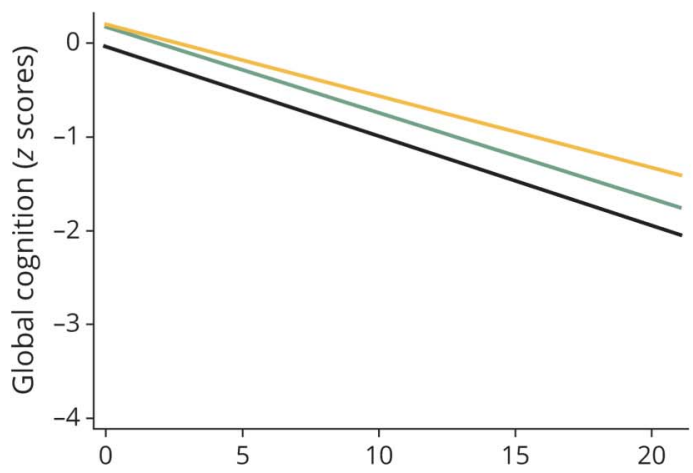

C. No gross infarcts

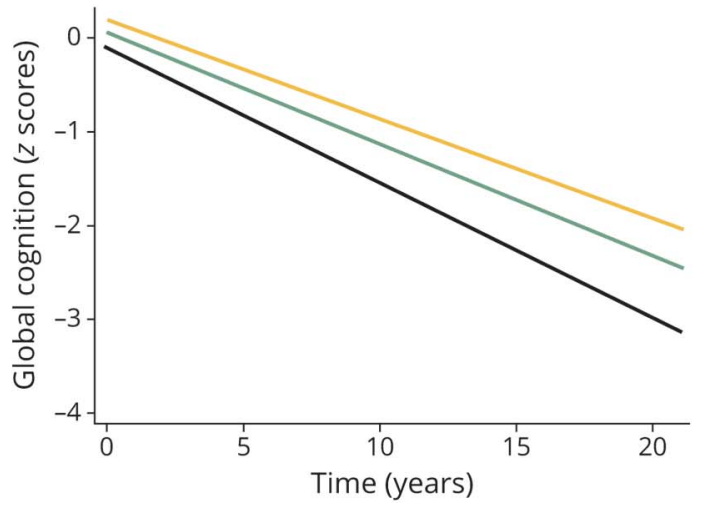

B. High global AD pathology burden

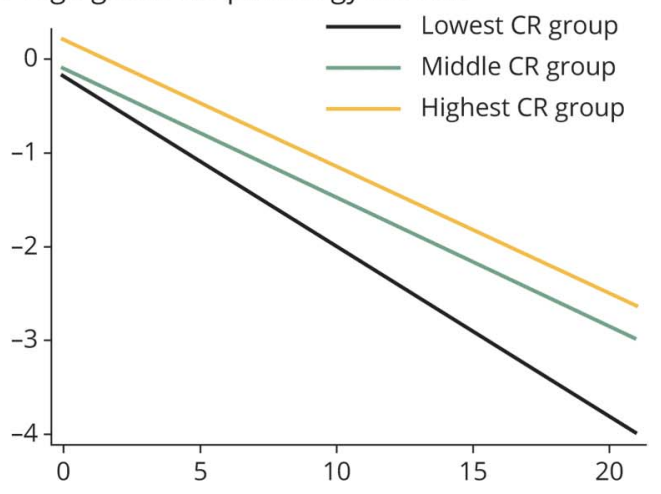

D. Any gross infarcts

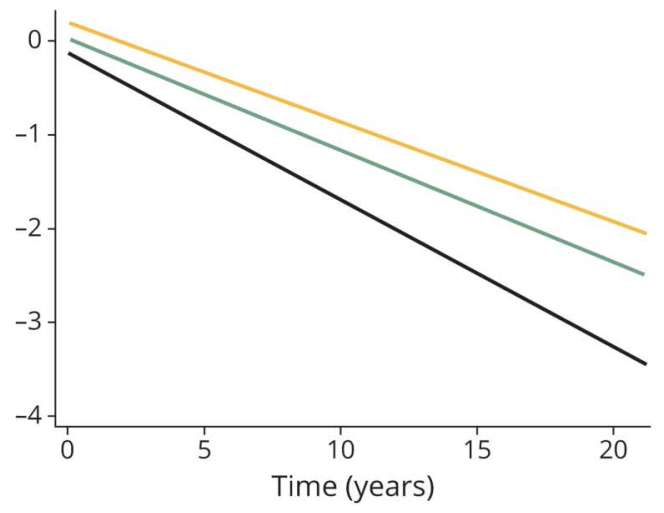

(A-D) Trajectories represent the values of $\beta$ coefficients from linear mixed-effect models adjusted for age, sex, body mass index, smoking, alcohol consumption, physical activity, hypertension, stroke, heart disease, diabetes, and APOE \&4. AD = Alzheimer disease.

functioning over time. We further found that the association of high CR with a slower cognitive decline remained significant in the presence of high $\mathrm{AD}$ pathology or gross infarcts. Our findings underscore the importance of educational and mentally stimulating activities throughout the lifespan for preserved cognitive function in late life. Further large population-based longitudinal studies are required to verify the effect of CR on cognitive decline and brain pathologies.

\section{Acknowledgment}

The authors thank the participants and staff involved in data collection and management in the Rush Memory and Aging Project.

\section{Study Funding}

Weili Xu received grants from the Swedish Research Council (2017-00981), the National Natural Science Foundation of China (81771519), Demensfonden, the Konung Gustaf V:s och Drottning Victorias Frimurare Foundation (2016-2020), and Alzheimerfonden (2017-2019). David A. Bennett received grants from the NIH (R01AG17917 and UH2NS100599). This project is part of CoSTREAM (costream.eu) and received funding from the European Union's Horizon 2020 research and innovation programme under grant agreement 667375 . Miia Kivipelto receives research support from the Stiftelse Stockholm Sjukhem, Wallenberg Clinical Scholars, and Center for Innovative Medicine (CIMED) at Karolinska Institutet.

\section{Disclosure}

X. Li, R. Song, X. Qi, H. Xu, and W. Yang report no disclosures relevant to the manuscript. M. Kivipelto receives research support from the Stiftelse Stockholm Sjukhem, Wallenberg Clinical Scholars, and Center for Innovative Medicine (CIMED) at Karolinska Institutet. D.A. Bennett received grants from the NIH (R01AG17917 and UH2NS100599). Weili $\mathrm{Xu}$ received grants from the Swedish Research Council (2017-00981), the National Natural Science Foundation of China (81771519), Demensfonden, the Konung Gustaf V:s och Drottning Victorias Frimurare Foundation (2016-2020), and Alzheimerfonden (2017-2019).The authors report no potential conflicts of interest. Go to Neurology.org/N for full disclosures.

\section{Publication History}

Received by Neurology February 9, 2021. Accepted in final form August 10, 2021. 
Appendix Authors

\begin{tabular}{lll}
\hline Name & Location & Contribution \\
\hline $\begin{array}{l}\text { Xuerui Li, } \\
\text { MSc }\end{array}$ & $\begin{array}{l}\text { Tianjin Medical University, } \\
\text { China }\end{array}$ & $\begin{array}{l}\text { Analyzed and interpreted the } \\
\text { data; drafted the manuscript; } \\
\text { performed statistical analysis; } \\
\text { revised the manuscript for } \\
\text { intellectual content }\end{array}$
\end{tabular}

\begin{tabular}{ll}
\hline Ruixue & Tianjin Medical University; \\
Song, MSc & Qilu Hospital of Shandong \\
& University, China
\end{tabular}

Analyzed and interpreted the data; performed statistical analysis; revised the manuscript for intellectual content

\begin{tabular}{|c|c|c|}
\hline $\begin{array}{l}\text { Xiuying } \\
\text { Qi, PhD }\end{array}$ & $\begin{array}{l}\text { Tianjin Medical University, } \\
\text { China }\end{array}$ & $\begin{array}{l}\text { Interpreted the data; revised } \\
\text { the manuscript for intellectual } \\
\text { content }\end{array}$ \\
\hline $\begin{array}{l}\text { Hui Xu, } \\
\text { PhD }\end{array}$ & $\begin{array}{l}\text { Beijing Children's Hospital, } \\
\text { China }\end{array}$ & $\begin{array}{l}\text { Interpreted the data; revised } \\
\text { the manuscript for intellectual } \\
\text { content }\end{array}$ \\
\hline $\begin{array}{l}\text { Wenzhe } \\
\text { Yang, } \\
\text { MPH }\end{array}$ & $\begin{array}{l}\text { Tianjin Medical University, } \\
\text { China }\end{array}$ & $\begin{array}{l}\text { Revised the manuscript for } \\
\text { intellectual content }\end{array}$ \\
\hline $\begin{array}{l}\text { Miia } \\
\text { Kivipelto, } \\
\text { MD, PhD }\end{array}$ & $\begin{array}{l}\text { Karolinska Institutet; } \\
\text { Karolinska University Hospital, } \\
\text { Stockholm, Sweden; Imperial } \\
\text { College London, UK }\end{array}$ & $\begin{array}{l}\text { Revised the manuscript for } \\
\text { intellectual content }\end{array}$ \\
\hline $\begin{array}{l}\text { David A } \\
\text { Bennett, } \\
\text { MD }\end{array}$ & $\begin{array}{l}\text { Rush University Medical } \\
\text { Center, Chicago, IL }\end{array}$ & $\begin{array}{l}\text { Designed and conceptualized } \\
\text { study; revised the manuscript } \\
\text { for intellectual content; major } \\
\text { role in the acquisition of data }\end{array}$ \\
\hline $\begin{array}{l}\text { Weili Xu, } \\
\text { PhD }\end{array}$ & $\begin{array}{l}\text { Tianjin Medical University, } \\
\text { China; Karolinska Institutet, } \\
\text { Stockholm, Sweden }\end{array}$ & $\begin{array}{l}\text { Designed and conceptualized } \\
\text { study; interpreted the data; } \\
\text { revised the manuscript for } \\
\text { intellectual content; major } \\
\text { role in the acquisition of data }\end{array}$ \\
\hline
\end{tabular}

\section{References}

1. Livingston G, Huntley J, Sommerlad A, et al. Dementia prevention, intervention, and care: 2020 report of the Lancet Commission. Lancet. 2020;396(10248):413-446.

2. Chételat G, La Joie R, Villain N, et al. Amyloid imaging in cognitively normal individuals, at-risk populations and preclinical Alzheimer's disease. Neuroimage Clin. 2013; 2:356-365.

3. Stern Y. Cognitive reserve in ageing and Alzheimer's disease. Lancet Neurol. 2012; 11(11):1006-1012.

4. Harrison SL, Sajjad A, Bramer WM, Ikram MA, Tiemeier H, Stephan BC. Exploring strategies to operationalize cognitive reserve: a systematic review of reviews. J Clin Exp Neuropsychol. 2015;37(11):253-264.

5. $\mathrm{Xu} \mathrm{H}$, Yang R, Qi X, et al. Association of lifespan cognitive reserve indicator with dementia risk in the presence of brain pathologies. JAMA Neurol. 2019;76(10): 1184-1191.

6. Rexroth DF, Tennstedt SL, Jones RN, et al. Relationship of demographic and health factors to cognition in older adults in the ACTIVE study. J Aging Health. 2013;25(8 suppl):128S-46S.

7. O'Shea DM, Fieo RA, Hamilton JL, Zahodne LB, Manly JJ, Stern Y. Examining the association between late-life depressive symptoms, cognitive function, and brain volumes in the context of cognitive reserve. Int J Geriatr Psychiatry. 2015;30(6): 614-622.

8. Zahodne LB, Nowinski CJ, Gershon RC, Manly JJ. Which psychosocial factors best predict cognitive performance in older adults? J Int Neuropsychol Soc. 2014;20(5): 487-495.

9. Jefferson AL, Gibbons LE, Rentz DM, et al. A life course model of cognitive activities, socioeconomic status, education, reading ability, and cognition. J Am Geriatr Soc. 2011;59(8):1403-1411.

10. Lavrencic LM, Churches OF, Keage HAD. Cognitive reserve is not associated with improved performance in all cognitive domains. Appl Neuropsychol Adult. 2018;25: 473-485.

11. Ritchie SJ, Bates TC, Der G, Starr JM, Deary IJ. Education is associated with higher later life IQ scores, but not with faster cognitive processing speed. Psychol Aging. 2013; 28(2):515-521.

12. Alley D, Suthers K, Crimmins E. Education and cognitive decline in older Americans: results from the AHEAD sample. Res Aging. 2007;29(1):73-94.
13. Staff R, Murray A, Deary I, Whalley L. What provides cerebral reserve? Brain. 2004; 127:1191-1199.

14. Zahodne LB, Glymour MM, Sparks C, et al. Education does not slow cognitive decline with aging: 12-year evidence from the Victoria Longitudinal Study. J Int Neuropsychol Soc. $2011 ; 17(6): 1039-1046$.

15. Vemuri P, Lesnick TG, Przybelski SA, et al. Association of lifetime intellectual enrichment with cognitive decline in the older population. JAMA Neurol. 2014;71(8): 1017-1024.

16. Leung GT, Fung AW, Tam CW, et al. Examining the association between participation in late-life leisure activities and cognitive function in community-dwelling elderly Chinese in Hong Kong. Int Psychogeriatr. 2010;22(1):2-13.

17. Foubert-Samier A, Catheline G, Amieva H, et al. Education, occupation, leisure activities, and brain reserve: a population-based study. Neurobiol Aging. 2012;33(2): 423-425.

18. Wilson RS, Scherr PA, Schneider JA, Tang Y, Bennett DA. Relation of cognitive activity to risk of developing Alzheimer disease. Neurology. 2007;69(20): 1911-1920.

19. Vaughan L, Erickson KI, Espeland MA, Smith JC, Tindle HA, Rapp SR. Concurrent and longitudinal relationships between cognitive activity, cognitive performance, and brain volume in older adult women. J Gerontol B Psychol Sci Soc Sci. 2014;69(6): 826-836.

20. Mousavi-Nasab S, Kormi-Nouri R, Nilsson L. Examination of the bidirectional influences of leisure activity and memory in old people: a dissociative effect on episodic memory. Br J Psychol. 2014;105(3):382-398.

21. Oveisgharan S, Wilson RS, Yu L, Schneider JA, Bennett DA. Association of early-life cognitive enrichment with Alzheimer disease pathological changes and cognitive decline. JAMA Neurol. 2020;77(10):1-8.

22. Richards M, Deary IJ. A life course approach to cognitive reserve: a model for cognitive aging and development? Ann Neurol. 2005;58(4):617-622.

23. Jones RN, Manly J, Glymour MM, Rentz DM, Jefferson AL, Stern Y. Conceptual and measurement challenges in research on cognitive reserve. J Int Neuropsychol Soc. 2011; 17(4):593-601.

24. Wang HX, MacDonald SW, Dekhtyar S, Fratiglioni L. Association of lifelong exposure to cognitive reserve-enhancing factors with dementia risk: a community-based cohort study. PLoS Med. 2017;14(3):e1002251.

25. Nelson ME, Jester DJ, Petkus AJ, Andel R. Cognitive reserve, Alzheimer's neuropathology, and risk of dementia: a systematic review and meta-analysis. Neuropsychol Rev. 2021;31(2):233-250.

26. Jagust WJ, Mormino EC. Lifespan brain activity, $\beta$-amyloid, and Alzheimer's disease. Trends Cogn Sci. 2011;15(11):520-526.

27. Bennett DA, Arnold SE, Valenzuela MJ, Brayne C, Schneider JA. Cognitive and social lifestyle: links with neuropathology and cognition in late life. Acta Neuropathol. 2014; 127(1):137-150.

28. Del Ser T, Hachinski V, Merskey H, Munoz D. An autopsy-verified study of the effect of education on degenerative dementia. Brain. 1999;122(12):2309-2319.

29. Bennett DA, Schneider JA, Buchman AS, Barnes LL, Boyle PA, Wilson RS. Overview and findings from the Rush Memory and Aging Project. Curr Alzheimer Res. 2012; 9(6):646-663.

30. Buchman AS, Boyle PA, Wilson RS, Bienias JL, Bennett DA. Physical activity and motor decline in older persons. Muscle Nerve. 2007;35(3):354-362.

31. Xu H, Yang R, Dintica C, et al. Association of lifespan cognitive reserve indicator with the risk of mild cognitive impairment and its progression to dementia. Alzheimers Dement. 2020;16(6):873-882.

32. Wilson RS, Yu L, Lamar M, Schneider JA, Boyle PA, Bennett DA. Education and cognitive reserve in old age. Neurology. 2019;92(10):e1041-e1050.

33. Marquine MJ, Segawa E, Wilson RS, Bennett DA, Barnes LL. Association between cognitive activity and cognitive function in older Hispanics. J Int Neuropsychol Soc. 2012;18(6):1041-1051.

34. James BD, Boyle PA, Buchman AS, Bennett DA. Relation of late-life social activity with incident disability among community-dwelling older adults. J Gerontol A Biol Sci Med Sci. 2011;66(4):467-473.

35. Buchman AS, Boyle PA, Wilson RS, Fleischman DA, Leurgans S, Bennett DA. Association between late-life social activity and motor decline in older adults. Arch Intern Med. 2009;169(12):1139-1146.

36. Barnes LL, Mendes de Leon CF, Wilson RS, Bienias JL, Evans DA. Social resources and cognitive decline in a population of older African Americans and whites. Neurology. 2004;63(12):2322-2326.

37. Song R, Xu H, Dintica CS, et al. Associations between cardiovascular risk, structural brain changes, and cognitive decline. J Am Coll Cardiol. 2020;75(20):2525-2534.

38. Wilson RS, Barnes LL, Krueger KR, Hoganson G, Bienias JL, Bennett DA. Early and late life cognitive activity and cognitive systems in old age. J Int Neuropsychol Soc. 2005;11(4):400-407.

39. Wilson R, Barnes L, Bennett D. Assessment of lifetime participation in cognitively stimulating activities. J Clin Exp Neuropsychol. 2003;25(5):634-642.

40. Bennett DA, Schneider JA, Aggarwal NT, et al. Decision rules guiding the clinical diagnosis of Alzheimer's disease in two community-based cohort studies compared to standard practice in a clinic-based cohort study. Neuroepidemiology. 2006;27(3): 169-176.

41. Bennett DA, Wilson RS, Schneider JA, et al. Natural history of mild cognitive impairment in older persons. Neurology. 2002;59(2):198-205.

42. Wilson RS, Boyle PA, Yu L, Barnes LL, Schneider JA, Bennett DA. Life-span cognitive activity, neuropathologic burden, and cognitive aging. Neurology. 2013;81(4): 314-321. 
43. Wilson RS, Boyle PA, Levine SR, et al. Emotional neglect in childhood and cerebral infarction in older age. Neurology. 2012;79(15):1534-1539.

44. Rodriguez FS, Zheng L, Chui HC; Aging Brain: Vasculature, Ischemia, and Behavior Study. Psychometric characteristics of cognitive reserve: how high education might improve certain cognitive abilities in aging. Dement Geriatr Cogn Disord. 2019;47(46):335-344.

45. Kaup AR, Nettiksimmons J, Harris TB, et al. Cognitive resilience to apolipoprotein E E4: contributing factors in black and white older adults. JAMA Neurol. 2015;72(3): 340-348.

46. Members ECC, Brayne C, Ince PG, et al. Education, the brain and dementia: neuroprotection or compensation? Brain. 2010;133(pt 8):2210-2216.
47. Valenzuela MJ, Matthews FE, Brayne C, et al. Multiple biological pathways link cognitive lifestyle to protection from dementia. Biol Psychiatry. 2012;71(9): 783-791.

48. Kempermann G, Gast D, Gage FH. Neuroplasticity in old age: sustained fivefold induction of hippocampal neurogenesis by long-term environmental enrichment. Ann Neurol. 2002;52(2):135-143.

49. Stern Y. What is cognitive reserve? Theory and research application of the reserve concept. J Int Neuropsychol Soc. 2002;8(3):448-460.

50. Wilson RS, Bennett DA, Bienias JL, Mendes de Leon CF, Morris MC, Evans DA. Cognitive activity and cognitive decline in a biracial community population. Neurology. 2003;61(6):812-816. 


\section{Neurology}

\section{Influence of Cognitive Reserve on Cognitive Trajectories: Role of Brain Pathologies}

Xuerui Li, Ruixue Song, Xiuying Qi, et al.

Neurology 2021;97;e1695-e1706 Published Online before print September 7, 2021

DOI 10.1212/WNL.0000000000012728

This information is current as of September 7, 2021

Updated Information \&

Services

References

Subspecialty Collections

Permissions \& Licensing

Reprints including high resolution figures, can be found at: http://n.neurology.org/content/97/17/e1695.full

This article cites 50 articles, 8 of which you can access for free at: http://n.neurology.org/content/97/17/e1695.full\#ref-list-1

This article, along with others on similar topics, appears in the following collection(s):

Cognitive aging

http://n.neurology.org/cgi/collection/cognitive_aging

Cohort studies

http://n.neurology.org/cgi/collection/cohort_studies

Information about reproducing this article in parts (figures,tables) or in its entirety can be found online at:

http://www.neurology.org/about/about_the_journal\#permissions

Information about ordering reprints can be found online:

http://n.neurology.org/subscribers/advertise

Neurology ${ }^{\circledR}$ is the official journal of the American Academy of Neurology. Published continuously since 1951, it is now a weekly with 48 issues per year. Copyright Copyright (C) 2021 The Author(s). Published by Wolters Kluwer Health, Inc. on behalf of the American Academy of Neurology.. All rights reserved. Print ISSN: 0028-3878. Online ISSN: 1526-632X.

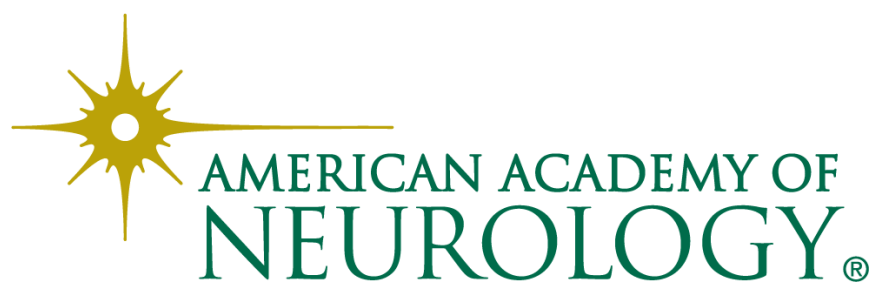

